average annual production during the last ten years. In addition to the resources at Cliffside, the U.S. Government possesses two helium reserves in Utah, which are being retained for future needs.

\section{Mineral Resources of the British Empire}

DurING the War of 1914-18 a Royal Commission formed the conclusion that an Empire Development Board was desirable, and there the project has been allowed to rest. An editorial article in Sands, Clays and Minerals (autumn issue, 1939) urges that no time should be lost in an intensive survey of the mineral resources of the Empire. The War, so far from causing a postponement of such a survey, should hasten it, and the survey must be carried out from a national point of view regardless of the possible financial profit that may accrue from the mining of any mineral. We cannot afford to wait while commercial interests debate the potential profit in a new venture: access to new supplies of a mineral ore may be vital to victory. The writer makes it clear that he is not thinking in terms of politicians and their methods of control. In that direction he foresees no hope of initiative. If anything is to be done, technologists will have to get together and do it for themselves.

It is proposed that the scientific men of Great Britain should draw up a scheme of Empire development, communicate it to corresponding groups in the Dominions and Colonies, and then give the plan such publicity that even the dead hand of the politician could not destroy it, and possibly some public-spirited men might launch the venture free from the shackles of official control. Emphasis is laid on the conception of a just minerals policy for the Empire in the peace that is to come, the necessity for preventing the exploitation of resources falling to the wrong kind of private enterprise in which profits are the one consideration, and finally the desirability of making the Empire's mineral resources available to all.

\section{An Artificial Mastoid for Audiphone Measurements}

THe Bell Laboratories Record of November 1939 contains a paper on the development of boneconduction audiphone receivers by M. S. Hawley, of the Transmission Instruments Engineering Department of the Laboratories. To provide a method of measuring the response of bone conduction receivers under the correct mastoid load, an artificial mastoid was developed. The impedance offered by the mastoid to a bone conduction receiver was measured on a number of people and then a rubber block was designed that presented to a receiver placed upon it approximately the same impedance as the average human mastoid. Since the artificial mastoid is based on average values of mastoid impedance, there may be slight variations in the results obtained with it and with some particular subject. The possible deviations are indicated by a diagram, which shows responses obtained with the artificial mastoid and with one particular subject. At very low frequencies here is an evident slight departure, but over the major part of the frequency range the results are in close agreement. Measurements on the same instruments made over a period of a year have shown very good correlation. Eventually the rubber pad ages and its impedance changes. The replacement of the old pad by a new one is a simple matter, so that the ageing of the rubber pad is not of much consequence. The artificial mastoid may be used in making other tests on receivers in which it is desired that the receiver be coupled to an impedance load equal to that of the head. Such tests include electrical impedance measurements, rattle tests, and nonlinear distortion measurements.

\section{Earth Tremor in New Jersey}

The United States Coast and Geodetic Survey, in co-operation with Science Service and the Jesuit Seismological Association, has now determined the epicentre of the earthquake of November 14, 1939, to have been near lat. $39^{\circ} 45^{\prime} \mathrm{N}$., long. $75^{\circ} 18^{\prime} \mathrm{W}$., which is only $10^{\prime}$ due south of the point suggested as being very near to the epicentre by the Franklin Institute at Philadelphia. The depth of focus is estimated as having been about $25 \mathrm{~km}$.

We are indebted to Prof. William A. Lynch, of Fordham University, New York, for the information that in the summer of 1938 a series of local shocks occurred to the north-east of the above epicentre in the region of lat. $40^{\circ} 8 \cdot \mathrm{N}$., long. $74^{\circ} 32^{\prime} \mathrm{W}$., the two most severe of which were on August 23 at $3 \mathrm{~h} .36 \mathrm{~m}$. and $7 \mathrm{~h} .3 \mathrm{~m}$. G.M.T. On the basis of a canvass of volunteer correspondents and observers, the Coast and Geodetic Survey then announced that the intensity of these "apparently did not exceed V according to the Modified Mercalli Scale of 1931" (felt by nearly everyone; many awakened; some dishes, windows, etc., broken; a few instances of cracked plaster, etc.). The earth tremor was not strong enough to be registered on the seismographs at Kew Observatory. "Earthquake History of the United States", part I (1938), published by the Survey, lists only four moderately strong earthquakes for New Jersey up to the year 1936. In our previous note on the earthquake (NATURE, Nov. 25, 1939 , p. 904) New Jersey was wrongly stated to be one of the New England States.

\section{Central European Observer}

WHEN the Czech nation lost its independence in 1620 its cultural life ceased. Yet Comenius and other teachers continued their educational work in exile. To-day, the nation is again under foreign domination, its universities and scientific institutions are closed and its cultural publications no longer appear in the country itself. One has, however, restamed publication in London. From 1923 until the end of 1938, there appeared in Prague the Central European Observer, a review in English dealing with science, art, literature and industry and with European affairs generally. In common with other Czech cultural reviews, it suspended publication after the virtual loss of independence in 1938. It is now appearing again as a fortnightly journal "to study, as it had done 